Imagining management education: a critique of the contribution of the United Nations PRME to critical reflexivity and rethinking management education.

Jill Millar*, Oxford Brookes University, Oxford, United Kingdom

Margaret Price, Oxford Brookes University, Oxford, United Kingdom

\begin{abstract}
Over 650 Business Schools worldwide have embraced the 2007 United Nations initiative, the Principles for Responsible Management Education (PRME). Proponents claim the initiative drives change and a fundamental rethinking of management education, through questioning and the challenging of assumptions. Critical discussions of PRME have been slower to emerge and this paper contributes a necessary critique. We relate claims of questioning and social change to ideas of critical reflexivity, including those of Margaret Archer, who presents it as an open-ended process of deliberation, generating social transformation. In so doing we ask whether PRME enables a critical reflexivity which might drive fundamental change in management education. Based on a critical discourse analysis of research data gathered in our United Kingdom Business School, we answer this question in the negative, arguing that PRME, far from promoting critical reflexivity, operates as an 'imaginary' to inhibit critical reflexivity, and to impose a particular agenda, limiting fundamental change. Rather it is resistance to the PRME agenda, and the availability of alternative imaginaries providing different meaning-making resources, which may contribute to a much needed rethinking of management education.

Key words: Management education, PRME, critical reflexivity, critical discourse analysis, imaginaries

${ }^{*}$ Corresponding author:

Jill Millar, Department of Business and Management, Oxford Brookes Business School

Oxford Brookes University, Headington Campus, Oxford, OX3 OBP

Email: jmillar@brookes.ac.uk 


\section{Imagining management education: a critique of the contribution of the United Nations PRME to critical reflexivity and rethinking management education.}

\section{Introduction}

There is a widespread perception, shared by critical scholars, business ethicists and mainstream management thinkers alike, that management education needs to be transformed. Central to these calls is the suggestion that Business Schools fail in their responsibilities to students, delivering a narrowly focussed curriculum that is over reliant on ideas of abstract rationality, scientific rigour and value neutrality (Colby et al., 2011; Dyllick, 2015; Waddock et al., 2010). Thus Business School educated managers lacked the moral capacity to deal with the recent financial crisis (Ghoshal, 2005), and remain unprepared to address crucial issues facing business in the 21 st century, including sustainability (Kurucz et al., 2014), and social justice, (Fotaki and Prasad, 2014; Toubiana, 2014). As a consequence management education should be fundamentally changed, (Beverungen et al., 2013), and students should be given an education that prepares them to be citizens of the world as well as business people (Colby et al., 2011; Koris et al., 2017), an education that reflects the role of Business Schools as social institutions with clear public responsibilities (Dyllick, 2015).

Concerns about management education are part of a broader conversation about economic and social challenges within capitalist economies. There is a growing unease about inequality (World Economic Forum, 2017), social unrest and populist politics (Murphy and Wilmott, 2015). In response it is argued that the capitalist economy itself should be rethought in order to address 'valid social frustrations' (World Economic Forum, 2017: xii), and that strategies should be adopted to make capitalism more inclusive (World Economic Forum, 2017) and egalitarian (Picketty, 2014 and Stiglitz, 2015).

Concomitant with re-found concerns about inequality and exclusion is the promulgation of a specific normative agenda for business. Increasingly there are expectations that businesses and business people will promote social responsibility and sustainable growth, expectations articulated in international and national initiatives including the United Nations Global Compact (2017) and the United Kingdom Government Call for Views on Corporate Responsibility (2014). 
Drawing directly on these ideas of how business should be practised, the United Nations Principles for Responsible Management Education (PRME), extend the application of social responsibility and sustainability from the field of business into management education, importing a sense of a moral compass. Ideas of corporate responsibility and global social responsibility (GSR) set out in the United Nations Global Compact are applied by PRME to what is taught in the business curriculum (Figure 1. Principle 2) and to academic activities more broadly (Figure 1. Principles 3-6). As a consequence PRME represents itself as a vehicle for rethinking management education, taking 'the case for universal values and business into classrooms on every continent' (PRME History, 2017). At the same time the purpose of business education is identified as developing 'future generators of sustainable value' (Figure 1. Principle 1), constituting a direct response to concerns about the type of managers emerging from Business Schools in recent years.

\section{The Principles for Responsible Management Education \\ As institutions of higher education involved in the development of current and future managers we declare our willingness to progress in the implementation, within our institution, of the following Principles, starting with those that are more relevant to our capacities and mission. We will report on progress to all our stakeholders and exchange effective practices related to these principles with other academic institutions: \\ Principle 1 | Purpose: We will develop the capabilities of students to be future generators of sustainable value for business and society at large and to work for an inclusive and sustainable global economy. \\ Principle 2 | Values: We will incorporate into our academic activities and curricula the values of global social responsibility as portrayed in international initiatives such as the United Nations Global Compact. \\ Principle 3 | Method: We will create educational frameworks, materials, processes, and environments that enable effective learning experiences for responsible leadership. \\ Principle 4 | Research: We will engage in conceptual and empirical research that advances our understanding about the role, dynamics, and impact of corporations in the creation of sustainable social, environmental, and economic value. Principle 5 | Partnership: We will interact with managers of business corporations to extend our knowledge of their challenges in meeting social and environmental responsibilities and to explore jointly effective approaches to meeting these challenges. \\ Principle 6 | Dialogue: We will facilitate and support dialog and debate among educators, students, business, government, consumers, media, civil society organizations and other interested groups and stakeholders on critical issues related to global social responsibility and sustainability. \\ We understand that our own organizational practices should serve as an example of the values and attitudes we convey to our students.}

Figure 1. The PRME Declaration (PRME Principles for Responsible Management Education, 2017) 
To date over 650 schools have signed up to PRME (PRME Home, 2017). Having become PRME signatories, participants are encouraged to embark on a course of continuous improvement, selfreporting their progress to interested stakeholders (PRME Overview, 2017). Despite its light touch voluntary nature, the PRME initiative is seen by many proponents as creating an opportunity to catalyse change in management education (Burchell et al., 2015; Fougere et al., 2014; Godemann et al., 2013; Maloni et al., 2012; Rasche and Escudero, 2010; Solitander et al., 2012), so as to 'meet the increasing societal demands for a responsible economy' (Godemann et al., 2013: 17). In providing a platform for wide ranging information sharing and learning activities, and identifying a set of broad principles as guidance, PRME is portrayed as offering a '(quite open) space [sic]' (Solitander et al., 2012: 341) or 'framework' (Fougere et al., 2014: 176), enabling a level of agency through which to 'spark organisational change' (Burchell, et al., 2015: 484). It is an opportunity 'not only to rethink what is being taught in business schools, but also to question the pillars upon which management education was built' (Rasche and Escudero, 2010: 246). This apparent capacity of PRME to drive fundamental change caught our interest as Business School academics, and provides the focus for this paper. Working in a United Kingdom Business School which has adopted PRME, we were interested to explore the extent to which PRME in practice contributes to a rethinking of management education. Does engagement with PRME allow colleagues within a Business School to question the pillars of management education?

The linkage of PRME to questioning and change aligns with ideas of reflexivity that have become an important theme within sociological analyses of social change (Caetano, 2015). In these analyses reflexivity is connected to change through the perceived need and capacity of social actors in modern societies to deliberate upon and question their social circumstances, which in turn generates social transformation (Archer, 2012). It is this sense of reflexivity, a critical reflexivity (Hibbert and Cunliffe, 2015), that underpins the expectation that staff will promote change and challenge the pillars of management education leading to a different way of understanding the purpose and content of the curriculum.

Underlying the capacity to exercise such a transformative critical reflexivity are questions of structure and agency, that is, the extent to which social actors actually have agency, including the agency to challenge and rethink social structures. In order to explore how far critical reflexivity is enabled in the context of PRME and management education we draw on critical discourse analysis (CDA) and 
insights from the work of Fairclough and Jessop. CDA offers a methodology for investigating the interaction of social structure and agency through focussing on 'discourse'. Following Fairclough (2003), we take discourse (singular) to refer in general terms to the structural resources, the forms of communication, used by social actors to produce meaning. Equally, we apply discourses (plural) to particular ways of representing the world (an example might be the discourse of employability in higher education). Within CDA discourse in both these senses is seen to 'more or less' (Fairclough, 2003: 25) structure social events, what is actually said and done by social actors within social practice, understood as 'relatively stabilised forms of social activity' (Fairclough, 2003: 205), such as management education. Adopting this perspective allows us to explore the way in which deliberations about management education are framed by discourse, and thus the extent to which critical reflexivity is possible. In particular, we adopt the idea of PRME as an 'imaginary', a specific assemblage of discourse or meaning making resources, in order to understand the nature of this framing (Jessop, 2012:5).

We use this theoretical platform to develop an analysis of the impact of PRME on staff conceptualizations of management education in our Business School. Our analysis responds to the proposition of PRME proponents that the initiative creates opportunities to question and change. Drawing on data relating to a research project on PRME implementation we illuminate the problem of relying on PRME to contribute to a fundamental rethinking of management education.

\section{Reflexivity and PRME}

There is a burgeoning literature on the value of reflexivity to business people, business leaders, researchers and students (Cunliffe, 2002; Cunliffe, 2009; Hibbert and Cunliffe, 2015; Maclean et al., 2012; Segal, 2012; and Sutherland, 2012). In this literature reflexivity is presented in a variety of ways, reflecting the range of theoretical perspectives that the authors bring to their analysis. Thus reflexivity involves 'complexifying thinking or experience by exposing contradictions, doubts, dilemmas and possibilities' (Cunliffe, 2002: 38); or 'questioning one's way of being' (Segal, 2012: 381), or 'the capacity of the actor to construct practical understandings of the location of the self within social systems', and the ability to act upon those understandings, reflecting upon and refining responses (Maclean et al., 2012: 388).Crucially, there seems to be general agreement about an important purpose of engagement in reflexivity, that is to 'help meet the dynamic experiential and 
highly subjective interactional contexts of contemporary organisational life', and as such it is a process of 'reflexive-self-work', (Sutherland, 2012: 33).

This understanding of reflexivity as a process of self-construction draws on the work of Margaret Archer. Archer conceptualizes social actors as consciously active, reflexive individuals who continuously deliberate on how to live their lives in accordance with their goals, values and commitments, or 'ultimate concerns' (Archer, 2012: 22). This focus on the individual means that a significant level of agency is attributed to social actors in their engagement with social structures and systems.

In her analysis, Archer distinguishes between different types of reflexivity, arguing that 'metareflexivity' is becoming a dominant form of reflexivity in the late modern era (2012:31). Metareflexivity involves a sense of a flexible social actor, guided by ultimate concerns, whose critical questioning drives social change (Archer 2012). This form of reflexivity is stressed by, for example, Hibbert and Cunliffe, who label it 'critical reflexivity' (2015: 180). Here reflexivity becomes more than self-work; it assumes that practitioners can step outside their social structures in order 'to be ready to question the social practices, organizational policies and procedures that we are involved in creating: to identify, advocate, and support necessary changes in situations that promote harmful values', (Hibbert and Cunliffe 2015: 180, referencing Giacalone and Thompson 2006). Building on these considerations the focus of our paper becomes: does PRME enable the critical reflexivity which might drive fundamental change?

In considering this question however we need to bear in mind that, as Farrugia and Woodman point out, social actors are not simply 'free to self-actualize through a meta-reflexive analysis of their own [goals]' (2015: 637). When exploring whether PRME enables critical reflexivity, there is a need to recognise that social structures can operate to constrain the agency of social actors to exercise critical reflexivity, and as a consequence, their ability to 'undermine structures and practices of domination' (Cunliffe, 2002: 37). It is to this notion of structural constraint that we now turn.

\section{Imagining management education}

As suggested above, a focus on discourse and meaning- making provides a way in to exploring the relation between social structure and individual reflexive action, and thus critical reflexivity. Fairclough's approach to discourse analysis, CDA, is particularly salient here. Eschewing Foucault's 
poststructuralist position, Fairclough acknowledges (2003: 22) that social actors have agency, that their actions are not 'totally socially determined', and that they interpret and represent what they do and say. At the same time, however, he argues that individuals are 'socially constrained' (Fairclough, 2003: 22), in that they operate within social practice. As already mentioned, the concept of social practice has a specific meaning, that of 'relatively stabilised forms of social activity' (Fairclough, 2003: 205), that have a structuring effect on social action. So, for example, treating academic work in management education as a social practice involves 'particular ways' of using space and language, acting and interacting, which operate to shape 'more or less' what is actually said and done by social agents (Fairclough, 2003:25). In other words it is here, in social practice, that the dialectical interaction between structure and agency is enacted. CDA is predicated on the understanding that discourse (and discourses) are central to this dialectic, in that these discourse elements in social practice 'constitute distinctive resources for meaning making' (Fairclough, 2010: 74), making some meanings available to social actors and precluding others. An example is the dominance in management education of what Ghoshal labelled the 'Chicago agenda', a discourse which promulgates a 'gloomy vision' of human nature as exclusively self- interested, at the expense of more nuanced and other- regarding understandings of human motivation (Ghoshal, 2005: 85). Fairclough captures this inclusive/exclusive effect by arguing that the discourse elements of social practice act as 'filtering mechanisms' (Fairclough, 2010: 74), selecting some meanings (people are self-interested) and excluding others (people are altruistic), with selected meanings in turn constituting social action, in this case in management education. The value of CDA, then, is to provide a way of understanding how discourse elements contribute to meaning-making, how they act as filtering mechanisms, and thus how they have an impact on critical reflexivity and individual action.

In conceptualizing the way that discourse elements act as filtering mechanisms, Fairclough (2001) and Jessop (2012) have developed the notion of 'imaginaries'. Imaginaries, they propose, are assemblages of such discourse elements, specified as genres (discourse in action, which in management education might include classroom discussions and programme meetings), discourses (for instance, employability, social responsibility and sustainability) and social identities (such as being a future generator of sustainable development). These assemblages operate, in Jessop's words, to 'frame individual subjects' lived experience of an inordinately complex world and/or guide collective calculation about that world' (2012: 5). 
Important ideas are condensed into this description of imaginaries. Firstly, there is an implication that imaginaries help to address the complexity of the world, enabling social actors to make sense of it and give it meaning by focussing selectively on some aspects rather than others (see discussion of imaginaries Jessop, 2012: 3-5). Secondly, this process of complexity reduction is not neutral, it 'frames' experience, making available some interpretations of the world and not others. Understood in this way imaginaries operate to constrain social actors, limiting the meaning making resources available to them. In terms of our preoccupation in this paper, this would suggest that any changes to management education will be informed by current and developing imaginaries of the nature and purpose of Business Schools.

Another important idea raised by Jessop's definition of imaginaries is that they operate at the collective as well as the individual level. Imaginaries are visions, representations of 'how things might or could or should be...projections of possible states of affairs, possible worlds' (Fairclough 2001: 234). Where such visions articulate with other discourses and resonate with influential social actors (actors with the ability to 'make a difference' (Jessop; 2012: 5)), they may be shared, becoming organizationally and institutionally 'fixed', or dominant, through interactions with material practices and relations (Fairclough and Fairclough, 2012: 103-109; Jessop, 2009: 4-5; 2012: 4). Potentially the PRME process reflects just such a trajectory, of a particular imaginary of management education in a re-moralized capitalist system, an imaginary which appears to resonate with a range of institutions and is accompanied by strategies for integrating change. Thus the 'light touch' PRME reporting requirements are reinforced by the focus of accreditation agencies on responsibility and sustainability, and combine to generate policies, 'technologies' (Jessop, 2009:3) that require and measure engagement with these concepts in accredited schools. Arguably then, it is becoming a vision of management education that both construes (interprets) and also constrains Business School practices.

Imaginaries are predicated on the basis of specific value assumptions, defined by Fairclough as the 'implicit meaning' that a particular situation or way of being is desirable (2003: 213). In the case of PRME, the principles explicitly state that the purpose of management education is to produce 'generators of sustainable value' and that ideas of responsibility, albeit lacking in clear definition, will be incorporated into management education. The value assumption here is that such a state of affairs is desirable and that this is how management education should be underpinned. 
Equally, imaginaries may be signalled in written and verbal texts as goals or aims (Fairclough and Fairclough, 2012), and again we find this with PRME, realized through the reiterated statement 'we will': we will incorporate particular values, we will develop educational frameworks, and so on (Figure 1). The goal focussed nature of PRME is also enacted through the adoption of a particular type of discourse in action, that of a global 'mission statement' for management education. As a consequence the PRME imaginary relates to what the outcomes, activities and values of management education should be, providing a particular vision of how management education should change.

In what follows we use CDA to illustrate the ways in which these elements of PRME, as imaginary, operate to limit the meanings available to our research participants in their discussion of management education. In so doing we show the impact of PRME on critical reflexivity and rethinking management education.

\section{Methodology: the PRME imaginary in a Business School}

Our data are derived from interviews conducted after an action research project, run in a United Kingdom Business School. The School had recently adopted PRME and the aim of the project was to enable staff and students to engage critically with PRME as part of a process of rethinking a programme for revalidation. As instigators of the project, we intended to run a series of sessions for colleagues, sessions designed to promote a process of inclusive debate, through which to explore the question of how the PRME principles should inform the new programme.

As a research project, participation was voluntary. Despite careful planning we were unable to obtain sufficient buy-in from staff to take part in the debate sessions or to implement the project as a piece of action research. To understand why this was the case we shifted our research focus from PRME implementation to PRME itself, and asked 'how do staff in our Business School respond to PRME?'. In order to answer this revised question we conducted interviews with staff.

The interviews, (lasting between 30 and 90 minutes), involved eight colleagues of the 32 originally eligible to take part in the action research project, that is staff who were responsible for developing the programme for revalidation (not including senior management and administrative support staff). The eight colleagues interviewed were purposively selected to include four individuals who had made themselves available to take part in the research project, and four who had not. These colleagues had 
backgrounds in teaching in business and management and/or marketing. Two, Morgan and Charlie, had leadership roles in the programme, the other colleagues interviewed were experienced lecturers. To preserve anonymity further details (including gender) which might lead to identification have been omitted from the interview extracts and from our discussion of them.

Initial thematic analysis of the interview data suggested that perceptions of the nature of management education, as well as the character of PRME, were factors in colleagues' responses to PRME. Here we take our analysis further by using the data collected to investigate how PRME, as an imaginary, informs visions of management education amongst our colleagues.

\section{Analysing the data}

As discussed, both Fairclough and Jessop suggest that imaginaries are assemblages or coagulations of discourse elements, genres, discourses and identities, which act as sources for meaning making, structuring ways of acting, representing and being within social practices (Jessop, 2009). The precise way that such assemblages operate is explored by Fairclough through detailed textual analysis (2001). His aim is to develop an understanding of how the different elements weave together within a particular discursive event, a research interview for example, and how such meanings relate to broader discursive structures within society (Fairclough, 2003). As such his approach permits a detailed and situated account of how meaning-making resources are combined to produce meaning, and using CDA we illustrate the ways in which meaning, in relation to management education and PRME, is realized in our data.

Thus we analyse the interview texts, focussing on the representations of management education that are achieved by the participants. To do so we point to discourses used, and consider how those discourses are articulated together. In so doing, we examine the traits that characterize the PRME imaginary itself, highlighting the assumptions and exclusions reproduced (or not) by our participants. Equally, in terms of identities, we focus on how participants operationalize their positions on PRME and management education through a concern with grammar and vocabulary. Here we consider modal tone, that is, the sense of commitment to the truth or necessity of a statement, realized through verbs and adverbs such as will/would/certainly/must, and also the vocabulary and pronouns used, and the forms of evaluation deployed. 
Fairclough (2003) suggests that research interviews have a communicative quality, in that they involve knowledge exchange and the development of understanding. It is this communicative quality that enabled us to explore our interviewee's critical reflexivity in connection with management education, as they examined and justified their ideas. The potential for critical reflexivity was enhanced by the interview format which began with the participants being encouraged to read through copies of the PRME principles. While reading they were asked to 'blackout' aspects of the principles with which they agreed or disagreed. It was left to the participant to decide what aspects of the text would remain visible and for what reason. The remainder of the interview then explored the responses that were prompted by this direct engagement with the PRME imaginary, the positions taken, visions expressed and assumptions made.

\section{Findings}

Analysing data from each interview using CDA has enabled us to develop an understanding of our interviewees' visions of management education. Here we focus on two key ideas that are central to the calls for change in management education with which we began this paper: the need for a moral compass, and the articulation of a social purpose for Business Schools. These ideas are reflected in the PRME imaginary in the stress on corporate responsibility, and the statement of the precise purpose of management education. Our focus allows us to examine the ways that participants responded to the imaginary, illustrates the extent to which their vision was structured by PRME, and thus the ways in which they engage with ideas of change.

\section{PRME and corporate responsibility}

At the heart of the PRME imaginary is the expectation that ideas of responsibility will underpin management education. The phrases social responsibility, responsible leadership and global social responsibility appear four times in the six short paragraphs of the principles (Figure 1). In this part of our findings we consider how a concern with responsibility is reflected in the interview texts, starting first with those of Alex and Morgan, who reproduce PRME's perspective on responsibility and management education, before moving on to the more nuanced positions of the other participants.

Alex's interview begins with Alex reading the PRME principles with a view to blacking out parts of texts with which s/he disagreed. The extract below forms part of the first exchange at the beginning of the interview. The PRME discourse is implicit in the extract, signalled by the pronoun 'it' (referring 
back to the proper noun PRME in the previous sentence) in statements such as 'it's all good stuff...' and referenced in the comments 'purpose and values is fine'. More explicit is the evaluative nature of these statements in connection to PRME: it is all good stuff; it is all valid; it is all good stuff, fairly simple stuff. The modal tone of the extract is expressed through the hedging phrase 'kind of' together with a repeated 'I think', which modalize the assertion 'it is all valid/good stuff', articulating a fairly strong commitment to the truth of the statements being made, ('I know' would be a stronger modalization, 'I suppose' would be weaker). Together with the evaluative quality of what is said, Alex articulates an acceptance of the PRME imaginary as a whole, and thus by implication the centrality of responsibility to management education. This is perhaps not surprising, given that Alex can be seen as a PRME champion within the Business School.

\author{
Alex: So I think my main responses are yes, it's all good stuff [text omitted to avoid \\ participant identification] \\ I: Right, so you'd want to leave the whole of the text? \\ Alex: I'd want to leave the whole text, yes, I kind of think it's all valid, it's good stuff and I \\ think it's fairly simple stuff.
}

Morgan was also a PRME champion, with a leadership role in the programme that was the focus of our research. In this extract, Morgan talks about the introduction of PRME to the programme. Building on a series of modalized statements, s/he realizes an expectation that PRME (represented by 'it') should be incorporated into the programme curriculum. This vision is reinforced by two categoric statements asserting that incorporation of such 'ethical responsible issues' has not been challenged. Morgan thus reproduces the PRME discourse, underpinned by a partially articulated value assumption, that the incorporation of ideas of ethics and responsibility is both necessary and unproblematic, an assumption reflected in the subordinate clause 'which is really reassuring I think'. Further in making these statements Morgan presents the notion that there is a consensus about the insertion of ethics and responsibility into management education, using the pronouns 'everyone', 'anyone' and 'we' which reinforce this assertion, while at the same time leaving the participants in the consensus unclear. Thus there appears uncertainty about the extent of the consensus on responsibility, combined with an acceptance that one exists. 
Morgan: Yeah and I do think that there is... I mean I would say that in my mind it feels like it's an assumed... everyone expects that we need to incorporate this and it's not something that anyone has actively questioned whether or not we should be incorporating ethical, responsible issues. I think everybody just thinks of course we do because that's what we should be doing, which is really reassuring I think.

Ronny, a lecturer on the programme, positioned her/himself within Morgan's consensus during our interview, as the extract below suggests. The reiterated phrase 'I think' modalizes Ronny's commitment to the assertion that it is right to include GSR within the curriculum, but at the same time the development of an evaluative statement including the adjectives 'important' and 'comfortable' strengthen the reproduction of PRME ideas.

Ronny: Regarding values I think it's right that we should include within our curricula the values of global social responsibility with the emphasis on 'global'... I think it's an important thing to encourage a set of values that see the importance of a sense of global social responsibility, so l'm quite comfortable with that as a principle.

Here Ronny begins to engage with the meaning of GSR by stressing the global quality of social responsibility. In contrast neither Morgan nor Alex address the question of what responsibility means in their response to PRME, replicating the lack of definition in the principles themselves. Indeed among our interviewees it was Lee, Sam, Charlie and Chris, all experienced lecturers and all colleagues who chose not to join our original action research project, who talked in more detail about what 'responsibility' actually means. Here we look at the positions taken by Chris, Lee and Sam.

Chris: 'I'm sorry, I'm OK with that [Principle 5] in broad... but I would want to if I was talking to anybody about this in depth, I would want to explore the meaning of the social responsibilities. For instance, is that taken to include political responsibilities? It should. Is it taken to include parenting responsibilities, community responsibilities?

In the first sentence of this extract Chris makes two initial modalized statements (I would, I would) which, combined with the contrastive adjectives (broad and depth) suggest that the meaning of responsibility requires exploration. This sentence is followed by two interrogatives (is it taken, is it taken) both of which (reinforced by the strongly modal statement of how things ought to be, 'it should') point to meanings which Chris attributes to responsibility. In seeking for definition, Chris is responding 
to the PRME imaginary, which leaves the question of what responsibility is (either GSR or corporate social responsibility) undefined. Indeed, Jonas Haertle, head of the PRME Secretariat argues the values of PRME are deliberately left ambiguous in order to allow a measure of local heterogeneity to intrude upon the 'internationally accepted values' - for them to be 'glocalised'. The principles, they suggest, should be used as a starting point for dialogue (Haertle and Miura, 2014:11- 13).

Lee echoes this understanding of the need for flexibility in interpreting the PRME principles when talking about the meaning of responsibility:

Lee: Social responsibility, OK what does that mean? Is that about supply chain issues, or is it broader than supply chain issues here, is that health \& safety? You know what's it about? And so I think that's broad enough, as long we don't need to then micro manage what global social responsibility is and say it's this, because in different subjects it's different things. Global social responsibility for me is about managing people fairly and in terms and conditions, and it's about pay and things like that, and about representation and voice and power, and the changing levels of power within the organization.

The extract starts with an open question, what does social responsibility mean, which Lee then goes on to answer. The next sentence is marked by a series of interrogatives 'is it?' organized around 'or', a conjunction which acts to set up 'supply chain/ broader supply chain/ health and safety' as equivalent understandings of social responsibility. Lee then elaborates upon the proposition that GSR has a variety of meanings, through the modalized statement 'I think it is broad enough', linked by another conjunction 'because', to the assertion that in different subjects it is different things. Also embedded in this sentence are the evaluative terms, 'broad', as contrasted with 'micro-manage' in the subordinate clause, which contribute to a suggestion that the meaning should not be prescribed. Again in contrast to Alex and Morgan, Lee then makes a series of assertions, only lightly qualified by the modal effect of 'for me', about what GSR actually does mean.

While Lee, and also Chris and Ronny, are more questioning about the meaning of responsibility than Alex and Morgan, they all reproduce the PRME assumption that responsibility is central to business practice and to management education, calling into question the extent of their critical reflexivity on this matter. In contrast Sam does not present PRME in the same way: 
Sam: The idea of, I don't know, of responsible management something, of responsible management, obviously makes sense to me but I suppose my starting point is that, well two things, I suppose $[X]$ years of experience or whatever and you've seen good and bad and to some extent I am worried that the whole movement, and that's not just the PRME movement but the wider ethical management movement, can sometimes lead to a focus on, if you like, almost organizational responsibilities rather than individual responsibilities and I think that's a real issue.

Over the course of the extract Sam differentiates between ideas of responsible management and the 'ethical management movement'. This distinction is developed in a complicated sentence where responsible management is contrasted (through the conjunction 'but') with Sam's 'starting point', which is that the ethical management movement focuses on organizational 'rather' than (another contrast) individual responsibilities. Here Sam expresses the value assumption, enhanced by use of the adjective 'real', that this characteristic of ethical management is a problem. Significantly, in treating PRME as a hyponym (a subcategory of a broader class) of the ethical management movement, Sam effectively distinguishes PRME from ideas of responsible management, in contrast to all the other colleagues interviewed. At the same time, Sam's comments are heavily modalized and hedged (I don't know; I suppose; well; I suppose; whatever; to some extent; sometimes; if you like; almost) suggesting a tentative commitment to the truth of the statements made, while also demonstrating the filtering effects of dominant discourses, with some meanings excluded or less available to social actors than others.

The purpose of management education

As suggested above PRME Principle 1 articulates a new and explicit purpose for management education (Figure 1), one that reflects its genesis in a period of corporate failure, in which Business School alumni were implicated or impotent (Dyllick, 2013; Godemann et al., 2013). Waddock et al., (2010) argue that the goal is to change not only understanding and attitudes, but also actions and behaviours, with the outcome being a particular product, 'a generation of responsible business leaders' (Godemann et al., 2013: 17). 
In this section we present our interviewees' responses to Principle 1, and the positions they took on the purpose of management education, considering extracts from interviews with Ronny, Morgan, Henri and Charlie, and starting with an exchange between one of the researchers and Lee.

I: I mean it is quite broad, it's almost motherhood and apple pie in a way, there's little to object to actually within the PRME?

Lee: $\quad$ Yeah, there is and that was the previous Dean's statement about [two clauses omitted to protect participant identity], 'Lee, this is motherhood and apple pie,' and I remember him saying that, but yes it is. But what it develops is what you might call heuristics, a quick response, my response to a situation is <snaps fingers> l'd manage it in a responsible way. So motherhood and apple pie, if it creates a gut [reaction] then you manage instantaneously in that way, rather than the other way, so I'm happy with motherhood and apple pie. That's fine, that's fine with me because it's a gut, it creates a gut and a gut is making a decision <snaps fingers> like that, and my response is not on the dark side of the empire, but on the good side. So I think that's fine to have that.

The interviewer proffers an evaluation of the PRME initiative, that it is 'motherhood and apple pie', an evaluation developed in the following clause that there is little to object to in PRME. Lee adopts this description of PRME, accentuated through her/his use of reported speech, before elaborating further. The conjunction 'but' (used twice) differentiates between the PRME initiative ('it') as simply unobjectionable, and the PRME initiative as promulgating a given. This perspective is proposed in the modalized statement that PRME operates as ('what you might call') a heuristic, an idea that Lee elaborates and strengthens over the course of the rest of the extract. Thus 'quick' 'responsible' and 'instantaneously' are applied to responses made as a result of PRME operating as a heuristic. This idea is developed further by the reiterated metaphor of 'gut', portraying PRME as generating reflex, as distinct from reflexive, judgements about management decisions. The juxtaposition of 'dark side'/'good side' (pivoting around 'but') reinforces Lee's position that this is a positive outcome of engagement with PRME (further emphasized by the adjectives 'happy' and 'fine').

Lee's position on PRME has implications for the outcomes of a management education framed by PRME. It implies that students may be conditioned to make responsible decisions as a matter of reflex, rather than engaging in a debate about what a responsible decision might be. This is a 
potential of PRME which raises concerns for Ronny, Morgan, Charlie and Henri as the following extracts illustrate.

In the first extract Henri considers the meaning of Principle 1.

Henri: I mean I could go and live on a commune after having done my MBA and is that working for an inclusive and sustainable global economy? Well not if I've become a hermit it isn't maybe. You can't tell me what to do.

I: No.

Henri: You can say that I should have the capability to make the decision and that that's what I'm choosing to do or not. So I'm working with the capability such that I am capable of working for an inclusive and sustainable global economy, whether or not I choose to do that; maybe that's better.

To begin with Henri explores two possible meanings of 'working for an inclusive and global economy', living in a commune and becoming a hermit. S/he discards both, the first implicitly through the use of the interrogative clause which undermines any equivalence between global economy and a commune, and the second explicitly through the modalized ('maybe') statement, 'well not if I have become'. This is followed by the central categoric assertion 'You can't tell me what to do'. This central proposition is then elaborated in the subsequent two sentences where s/he offers an alternative vision of Principle 1, expressed through the use of the modal verbs 'can' and 'should'. In this vision, students may have developed relevant capabilities while at university, but they do not have to act upon them, a vision strengthened by reiteration of the word 'choose'.

Ronny, too, focuses on the meaning of Principle 1, specifically in connection with the actual development of capabilities relevant to a sustainable economy.

Ronny: I think I might go the other way and focus on the issues that I disagree with. I don't believe that it is possible to develop the capabilities of students to be future generators of sustainable value. And the reason I don't believe you can give students the capacity to understand the issues and you can offer them encouragement, if you like, to make the right kind of decisions but I don't think you can engender in them the capabilities because ultimately responsibility is a very individual thing in how people perceive it. So some people 
are led by conscience and by a higher sense of purpose; some people are led by self-interest and will seek ways of rationalising what ultimately boils down to self-interest. So I think as educators we have a responsibility to enable students to recognize what the issues are to understand the significance of the issues, to recognize the consequences if you like, of choosing the wrong path.

Here Ronny makes a series of statements whose subjective modality (the repeated 'I don't believe', I don't think. I think) associate her/him fairly strongly with the truth of what is being said. In discussing Principle 1, Ronny begins by stating that it is not possible to develop the capabilities of students to be future generators of sustainable value, a position elaborated in the next sentences. Crucial to this elaboration is the distinction made between what can be done (give capacity; offer encouragement) and what cannot be done 'engender capabilities', again achieved through the conjunction 'but'. While capability and capacity could be understood as interchangeable, Ronny differentiates between the two, attributing innate qualities to the idea of capability, through the assertion that responsibility is a 'very individual thing'. Thus, responsibility cannot be created it can only be encouraged. This understanding is developed further in the next sentence, by the coordinating conjunction 'so', which contributes the sense of consequence to Ronny's statements: responsibility is individual so people are led by different priorities. The final sentence in this extract also begins with a consequential 'so', stating that what educators should do, and here the vision is explicit, is enable students to understand and to recognize. By implication then, what educators cannot do is seek to impose a particular way of being or set of behaviours upon students.

This position is echoed by the other colleagues interviewed (except Alex). Morgan distinguishes between imposition and enablement in the following sentence which pivots around a contrastive 'but': 'So it's about developing the capabilities of students, but doing it with them, not to them, if you see what I mean', while Charlie makes a similar point 'it is our responsibility to make sure that the students are aware of the debates taking place around ethics, but it is not up to us to tell them what those values should be'. Taken together, the distinctions made by these interviewees between engendering/ enabling, doing to/with and tell/explore, all operate to suggest a vision of what the purpose and outcomes of management education should be, which contrasts with the explicit goal of Principle 1, and the embodied notion of responsibility articulated by Lee. Rather than reproducing the PRME imaginary and the notion that students should be inculcated with a particular way of being, 
colleagues appear to draw on a range of pedagogic discourses, such as the idea of reflexive practicestudents encouraged to address complexity and promote social change, but crucially without preordained goals- to represent the purpose of management education.

\section{Discussion}

Using our findings we now expand upon the way the PRME imaginary serves to structure reflexive engagement with ideas of responsibility and management education. In so doing we suggest that PRME as an imaginary, with a particular vision of management education, filters the meanings available to colleagues, inhibiting critical reflexivity and the ability to question practices and support necessary change, (contra the proposition of PRME proponents, including Burchell et al., 2015; Fougere et al., 2014; Rasche and Escudero, 2010 and Solitander et al., 2012). Equally, we argue that resistance to the PRME imaginary, apparent in the attempts by colleagues to draw on alternative discourses, may create space for a more fundamental rethinking of management education.

At first sight the way that Lee and Chris respond to the PRME imaginary, with both proffering accounts of what responsibility means, suggests a flexibility of meaning in PRME in relation to responsibility. Indeed it is perhaps not surprising that different ideas emerge, given the lack of definition of responsibility in Principle 2 already mentioned. However, that there is a limit to any flexibility of meaning is illustrated by Sam's position on PRME and responsibility. In presenting responsibility as in practice being about organizational responsibility rather than about responsible management, or as a concern with corporate reputation (Hanlon and Fleming, 2009), Sam challenges PRME's reliance on GSR. This is potentially an uncomfortable position to take, a discomfort which seems to be expressed in the heavily modalized and hedged way in which Sam articulates her/his viewpoint. Thus while it may be claimed that there is space within the PRME imaginary to debate ideas of the responsibilities of business to society, and to develop and share particular glocalised versions of GSR or corporate responsibility that are appropriate to local contexts (Haertle and Miura, 2014), there may not be space to critique or reject GSR or corporate responsibility altogether, limiting the possibility for critical reflexivity.

A further barrier to critical reflexivity is highlighted by an important gap in our data: none of our informants commented on the assumption of universality that appears to be integral to PRME. PRME proponents make frequent references to PRME values as being internationally proclaimed or 
accepted (Alcaraz and Thiruvattal, 2010; PRME Overview, 2016; Sobczak and Mukhi, 2016; Waddock et al., 2010). There is though, an important difference between international proclamation and universal acceptance. As argued elsewhere (Millar and Koning, forthcoming 2018) the conceptualization of responsibility promulgated by PRME is an instance of re-scaling, the disembedding of local and particular understandings of the nature and purpose of economic activity, which have been reframed as a universal programme. As a consequence other, subaltern, understandings of responsibility and business (for example Mitra, 2012) are excluded. Thus the opportunity for glocalisation identified by Haertle and Miura (2014), is only an opportunity for such alternative understandings to be aligned with PRME 'universal' values, not to reconfigure them, or reject them altogether (Vizureanu, 2013). As the gap in our data suggests, there is a lack of available discourses within the imaginary through which alternative positions on the PRME values could be developed to inform a critical reflexivity.

Another way in which the PRME imaginary sets boundaries to a rethinking of management education is through the idea of consensus. We note in our findings that Morgan realizes a sense of consensus about the need to incorporate ethics and responsibility into management education through deployment of the pronouns 'everyone', 'anyone' and 'we'. In so doing, Morgan reproduces the assumed consensus (Louw, 2015) of PRME, that ideas of responsibility should inform management education. In the principles themselves this is achieved through the reiteration of the pronoun 'we' throughout the text. As Louw (2015) states, the subject positions reflected in the use of 'we' shift across the principles, between an institutional 'we' to a 'we' as the Deans of Business Schools. Indeed the 'we' could also be taken to refer to the concrete PRME 'collaborative community' (Haertle and Miura, 2014) and to an abstract global academic community. It appears then that not only is a there a lack of available discourses through which to develop alternative subject positions on PRME values, but that no such alternative subject positions would be possible, since 'we' are all already in agreement, whoever 'we' are. Again the PRME imaginary appears to inhibit the stepping outside of one's circumstances required by critical reflexivity.

The claiming of consensus connects to a further way in which PRME limits critical reflexivity. Returning to our data it is noticeable that while the meaning of 'responsibility' associated with PRME was explored, none of our colleagues (not even Sam) queried or rejected that social responsibility per se should be an underpinning value for management education. The necessity for Business Schools 
to teach, and businesses to enact social responsibility appears as a given. It is as Lee agreed, equivalent to 'motherhood and apple pie'. What we are seeing here, we suggest, are signs of what Jessop describes as the sedimentation of meaning (Jessop, 2012). This evocative term is used to suggest that as particular imaginaries are adopted and are increasingly embedded (sedimented), there is a 'forgetting' of the 'contested origins of discourses, structures and processes' (Jessop, 2012: 5). Yet the attributing of social responsibility to business reflects a particular understanding of the relation between business and society and obscures the historically situated origins of this understanding. It is an understanding in which broader social responsibilities are seen as additional to, rather than integral within, business practice, reflecting a founding assumption of economic theory, that rational actors act in terms of their own self- interest (del Portal and de Frutos, 2015). This is a distinction which continues to haunt current corporate responsibility debates, again reducing the scope for a critical reflexivity among our interviewees.

So far we have identified four ways in which PRME as an imaginary promulgates particular meanings of social responsibility within business and management education and excludes others. Indeed as our data suggest, colleagues (with the exception of Sam) do not question the notion social responsibility per se. PRME then appears as a dominant discourse, an imaginary that is resonant with social actors, that colleagues have come to 'own' and 'to position themselves inside', 'to act and think and talk and see themselves in terms of' (Fairclough, 2001: 235). Equally, as Sam's extract shows, it can be difficult to challenge dominant discourses. As a consequence critical reflexivity, as an open ended stepping outside of structures in order to question fundamental values of management education, is inhibited. Yet this is not the whole story. As both Fairclough and Jessop suggest, there is no inevitability that any imaginary will become or remain dominant within social practices or specific institutions. Imaginaries are only ever partially constituted (Jessop, 2012), and there are always loose ends which do not fit, creating the potential for the imaginary to unravel and lose dominance. Relevant here is Fairclough's recognition that while imaginaries structure action, social actors are not 'totally socially determined' (2003: 22). There remains scope for resistance, for social actors to respond to the filtering effects of dominant or increasingly dominant imaginaries, by drawing on alternative discourses. In our data the way that Henri, Ronny, Morgan and Charlie conceptualize the purpose of management education would seem to represent just such a resistance. 


\section{Conclusion}

Our purpose has been to explore the extent to which PRME promotes critical reflexivity and the rethinking of management education in a Business School, understood as a transformation in which underpinning assumptions are debated and reworked. We conclude our exploration by making the following two points:

Firstly, we have argued that PRME operates as an imaginary, as a vision of how management education should be. As such it provides a recipe for reconfiguring management education, one that contains its own presuppositions that are not open to question. Thus it has the potential to introduce a particular way of thinking about what is taught and why in Business Schools, but it does not offer in itself a space for critical reflexivity, where fundamental understandings of nature or management education and business practice can be engaged with and challenged. By incorporating a concern with responsibility into curriculum and research PRME introduces a moral focus to management education, which undermines narrow functionalist pedagogies and practices, a focus that is reproduced by our research participants. However fundamental assumptions about the individualist and self- interested nature of business remain untouched.

Secondly, PRME as an imaginary appears to be at least partially dominant within our Business School, shaping our colleagues' interpretations and representations of management education. Significantly though it is not fully dominant, and it is this incomplete dominance that creates opportunities for colleague to resist PRME by drawing on alternative 'reservoirs' of meaning-making resources (Jessop, 2012: 4), as we have seen in their representations of the purpose of management education. Arguably it is here, in the interstices between imaginaries, not within PRME, but between PRME and other imaginaries of management education, that opportunities exist to exercise critical reflexivity, enabling a more fundamental rethinking of management education that can meet the concerns of those calling for change.

\section{Acknowledgements}

The authors gratefully acknowledge the insights and support given during the development of this article by the editor, anonymous reviewers, and colleagues (especially Karen Handley and Birgit den Outer). 


\section{Funding statement}

The research on which this article is based was supported by the British Academy [SG111155].

\section{References}

Alcaraz J and Thiruvattal (2010) An interview with Manuel Escudero: The United Nations Principles for Responsible Management Education: A global call for sustainability. Academy of Management Learning \& Education, 9(3): 542-550.

Archer M (2012) The reflexive imperative in late modernity. Cambridge: Cambridge University Press.

Beverungen A, Dunne S and Hoedemaekers, C (2013) The financialisation of business ethics.

Business Ethics: A European Review, 22(1): 102-117.

Burchell, J, Kennedy S and Murray, A (2015) Responsible management education in UK business schools: Critically examining the role of the United Nations Principles for Responsible Management Education as a driver for change. Management Learning, 46(4): 479-497.

Caetano A (2015) Defining personal reflexivity: A critical reading of Archer's approach European Journal of Social Theory, 18(1): 60-75.

Colby A, Ehrlich T, Sullivan W, Dolle J and Shulman L (2011) Rethinking undergraduate business education: Liberal learning for the profession. California: Josey Bass.

Cunliffe A (2002) Reflexive dialogical practice in management learning. Management Learning, 33(1): $35-61$.

Cunliffe A (2009) The philosopher leader: On relationalism, ethics and reflexivity-A critical perspective to teaching leadership. Management Learning 40(1): 87-101.

Del Portal E and de Frutos S (2015) Corporate social responsibility: a critical review Ramon Llull Journal of Applied Ethics, (6): 125-136.

Dyllick T (2015) Responsible management education for a sustainable world. Journal of Management Development, 34(1): $16-33$.

Fairclough N (2001) The dialectics of discourse. Textus 14(2): 231-242.

Fairclough N (2003) Analysing discourse: textual analysis for social research. London: Routledge. 
Fairclough N (2010) Critical discourse analysis: the critical study of language 2nd edition Essex: Longman.

Fairclough I and Fairclough N (2012) Political discourse analysis: a method for advanced students. Abingdon: Routledge.

Farrugia D and Woodman D (2015) Ultimate concerns in late modernity: Archer, Bourdieu and reflexivity. The British Journal of Sociology, 66(4): 626-644.

Fotaki M and Prasad A (2014) Social justice interrupted? Values, pedagogy, and purpose of business school academics. Management Learning, 45(1): 103-106.

Fougère M, Solitander N and Young S (2014) Exploring and exposing values in management education: Problematizing final vocabularies in order to enhance moral imagination. Journal of Business Ethics, 120(2): 175-187.

Ghoshal S (2005) Bad management theories are destroying good management practices. Academy of Management and Learning Education, 4(1): 75-91.

Godemann J, Haertle J and Herzig C and Moon J (2013) United Nations supported Principles for Responsible Management Education: purpose, progress and prospects. Journal of Cleaner Production, 62(2014): 16-23.

Haertle J and Miura S (2014) Seven years of development: United Nations-supported Principles for Responsible Management Education. SAM Advanced Management Journal, 79(4): 8-17.

Hanlon, G and Fleming P (2009) Updating the Critical Perspective on Corporate Social Responsibility Sociology Compass, 2/6 (2009): 1-12.

Hibbert P and Cunliffe A. (2015) Responsible management: Engaging moral reflexive practice through threshold concepts. Journal of Business Ethics, 127(1): 177-188.

Jessop B (2009) Cultural political economy and critical policy studies. Critical Policy Studies, 3(3-4): 336-356.

Jessop B (2012) Imagined recoveries, recovered imaginaries: A Cultural Political Economy Perspective. Available at:www.lancs.ac.uk/cperc/docs/E-2012\%20Jessop-CPESwanseaRecovery.pdf (accessed 24 August 2017). 
Koris, R, Ortenblad A and Ojala T (2017) From maintaining the status quo to promoting free thinking and inquiry: Business students' perspective on the purpose of business school teaching Management Learning, 48 (2): 174-186.

Kurucz E, Colbert B and Marcus J (2014) Sustainability as a provocation to rethink management education: Building a progressive educative practice. Management Learning, 45(4): 437-457.

Louw J (2015) "Paradigm Change" or no real change at all? A critical reading of the U.N. Principles for Responsible Management Education. Journal of Management Education, 39(2): 184-208.

Maclean M, Harvey C and Chia R (2012) Reflexive practice and the making of elite business careers. Management Learning, 43(4): 385-404.

Maloni M, Smith S and Napshin S (2012) A methodology for building faculty support for the United Nations Principles for Responsible Management Education. Journal of Management Education, 36(3): 312-336.

Millar, J and Koning, J (forthcoming, 2018) From capacity to capability? Rethinking the PRME agenda for inclusive development in management education African Journal of Business Ethics.

Mitra R (2012) 'My Country's Future': A culture-centred interrogation of corporate social responsibility in India. Journal of Business Ethics 106(2): 131-147.

Murphy J and Willmott, $\mathrm{H}(2015)$ The Rise of the 1\%: An organizational explanation, In: Morgan, Hirsch and Quack (eds) Elites on Trial (Research in the Sociology of Organizations, Volume 43). Bingley: Emerald Publishing Limited pp: 25-53.

Picketty T (2014) Capital in the Twenty First Century (trans. Goldhammer). London: Belknap Press. PRME (2017) History. Available at: http://www.unprme.org/about-prme/history/index.php (accessed 10 March 2017).

PRME (2017) Home Available at: http://www.unprme.org/index.php (accessed 10 March 2017)

PRME (2017) Overview. Available at: http://www.unprme.org/about-prme/index.php (accessed 10 March 2017) 
PRME (2017) Principles for responsible management education. Available at:

http://www.unprme.org/about-prme/the-six-principles.php (accessed 25 February 2017)

Rasche A and Escudero M (2010) Leading change. Zeitschrift Fuer Wirtschafts- Und

Unternehmensethik, 10(2): 244-250.

Segal S (2012) A Heideggerian approach to practice based reflexivity. Management Learning, 41(3): 379-389.

Sobczak A and Mukhi U (2016) The Role of UN Principles for Responsible Management Education in stimulating organizational learning for global responsibility within Business Schools: An interview with Jonas Haertle. Journal of Management Inquiry, 25(4): 431-437

Solitander N, Fougere M, Sobczak A and Herlin H (2012) We are the champions: Organisational learning and change for responsible management education. Journal of Management Education, 36(3): 337-363.

Stiglitz J (2015) The Great divide: Unequal societies and what we can do about them. New York: WW Norton and Company.

Sutherland I (2012) Arts-based methods in leadership development: affording aesthetic workspaces, reflexivity and memories with momentum. Management Learning, 44(1): 25-43.

Toubiana M (2014) Business pedagogy for social justice? An exploratory investigation of business faculty perspectives of social justice in business education. Management Learning, 45(1): 81-102.

United Nations (2017) Global compact. Available at https://www.unglobalcompact.org/ (accessed 21 August 2017).

United Kingdom Government (2014) Good for business and society: government response to call for views on corporate responsibility. Report, Department for Business Innovation and Skills. UK.

Vizureanu V (2013) Some remarks concerning the concept of glocalization. Public Reason, 5 (1): 6986. 
Waddock S, Werhane P and Rasche A (2010) The principles for responsible management education - where do we go from here? In: Fisher D and Swanson D (eds.) Assessing Business Ethics Education. Charlotte: Information Age Publishing, pp13-28.

World Economic Forum (2017) The Inclusive growth and development report. Available at: https://www.weforum.org/reports/the-inclusive-growth-and-development-report-2017 (accessed 1 March 2017). 